\title{
Strain Ultrasound Elastography of Muscles in Healthy Children and Healthy Adults
}

\section{Strain-Ultraschallelastografie der Muskulatur bei muskelgesunden Kindern und Erwachsenen}

Authors

Helena Wenz ${ }^{1}$, Andrea Dieckmann², Thomas Lehmann ${ }^{3}$, Ulrich Brandl², Hans-Joachim Mentzel ${ }^{1}$

Affiliations

1 Section of Pediatric Radiology, Institute of Diagnostic and Interventional Radiology, University-Hospital Jena, Germany

2 Department of Pediatric Neurology, University-Hospital Jena, Germany

3 Institute of Medical Statistics, Computer Sciences and Documentation, University-Hospital Jena, Germany

Key words

muscle elasticity, strain elastography, ultrasound

elastography, children

received 12.10 .2018

accepted 04.03.2019

Bibliography

DOI https://doi.org/10.1055/a-0889-8605

Published online: 29.4.2019

Fortschr Röntgenstr 2019; 191: 1091-1098

(c) Georg Thieme Verlag KG, Stuttgart · New York

ISSN 1438-9029

Correspondence

Prof. Hans-Joachim Mentzel

Pädiatrische Radiologie, Institut für Diagnostische und

Interventionelle Radiologie

Klinikum der Friedrich-Schiller-Universität Jena,

Erlanger Allee 101, 07740 Jena, Germany

Tel.: ++49/3641/938337

Fax: $++49 / 3641 / 938257$

hans-joachim.mentzel@med.uni-jena.de

\section{ABSTRACT}

Purpose Standardized application and evaluation of the strain ultrasound elastography method (USE) by means of a strain color scale (SCS) and a strain ratio analysis. To determine differences in muscle elasticity in healthy children and adults.

Materials and Methods Initially Mm. biceps brachii, Mm. recti femoris and $\mathrm{Mm}$. gastrocnemii of 22 healthy adults were examined before and after exercise. Secondly measurements were obtained at rest in 21 healthy children.
Results There was a difference in muscle elasticity between the upper and lower extremity. Muscle elasticity tends to be higher after exercise in healthy adults. SCS and strain ratio analysis show a similar trend. In comparison to adults, healthy children show lower muscle elasticity at rest using both analysis methods.

Conclusion Strain elastography is an easy to perform, costeffective, non-invasive method to determine muscle stiffness, if the conditions of standardized measurements are given.

Key Points:

- It is possible to perform standardized measurements with the strain elastography method in healthy adults and children

- Strain color scale as well as strain ratio analysis are appropriate tools to interpret the elastogrammes

- strain elastography shows higher elasticity in adults' muscles after exercise

- strain elastography shows higher elasticity in adults' muscles than in muscles of healthy children

\section{Citation Format}

- Wenz H, Dieckmann A, Lehmann T et al. Strain Ultrasound Elastography of Muscles in Healthy Children and Healthy Adults. Fortschr Röntgenstr 2019; 191: 1091-1098

\section{ZUSAMMENFASSUNG}

Ziele Standardisierte Anwendung und Auswertung der Strain-Ultraschallelastografie (USE) anhand von Farbskalaund Deformationsquotienten-(Strain-Ratio)-Analyse. Ermittlung von Elastizitätsunterschieden der Muskulatur bei muskelgesunden Kindern und Erwachsenen.

Material und Methoden Es wurden 22 Erwachsene (2030 Jahre) und 21 Kinder (2 - 12 Jahre) beidseits an den Mm. biceps brachii, Mm. recti femoris sowie Mm. gastrocnemii nach einer Ruhephase elastografisch untersucht. Bei Erwachsenen erfolgten zudem Messungen nach standardisierter muskulärer Beanspruchung.

Ergebnisse Es fanden sich Unterschiede zwischen den Ruhewerten der Arm- und Beinmuskulatur sowie zwischen den Geschlechtern. Farbskala- und Deformationsanalyse zeigten ähnliche Tendenzen. Bei Erwachsenen fand sich eine höhere Elastizität nach muskulärer Beanspruchung. Die muskelgesunden Kinder wiesen in Ruhe signifikant niedrigere Muskelelastizitäten auf als Erwachsene. 
Schlussfolgerung Die Strain-Elastografie ist eine einfache, kostengünstige, nichtinvasive Methode zur Beurteilung der elastischen Eigenschaften der Muskulatur, wenn die Voraus- setzungen für standardisierte Messungen und Auswertungen gegeben sind.

\section{Introduction}

Ultrasound elastography (USE) is based on fundamental sonography and is an innovative, non-invasive diagnostic method for assessing the elastic properties of tissues. To date, strain elastography has been used primarily in oncology to assess the stiffness and elasticity of focal masses [1].

During strain elastography/real time USE, the examiner provokes tissue deformation (strain) via the ultrasound head. Hard tissue is less deformable than soft, elastic tissue [1 - 3]. Strain elastography analysis compares the internal ultrasound propagation before and after moderate stress as well as comparing the relative tissue deformation of an area to its surroundings, resulting in an elastogram projected onto the B-mode ultrasound image showing elasticities in real time using color differences [4].

Frequently, red represents softer tissue, and blue shows harder tissue. Elasticity can be assessed by the evaluation of the color distribution purely qualitatively or semi-quantitatively by the assignment of point values according to the color distribution (e. $g .1$ = red $=$ soft to $5=$ blue $=$ hard). With some devices it is possible to calculate a strain ratio as a numerical value which is calculated based on the tissue deformation of a reference region divided by the tissue deformation of another region of interest (ROI) $[1,2,4]$.

Initial studies of sonographic determination of muscle elasticity are available, which, however, are based on the heterogeneity of the respective study designs (e.g. different sonography devices, experience of the investigator, different numbers of cases and age of the subjects); likewise due to the hitherto insufficiently standardized application of strain elastography and differentiated evaluation of the elastograms, they are difficult to compare with one another [4-8].

Thus, contradictory conclusions were achieved by Yanagisawa et al., who used strain USE before and after muscular exercise in adults, and a study by Berko et al., which elastographically determined the muscle elasticity of children before and after standardized exercises. While Yanagisawa et al. showed decreased elasticity in adults after exercise, USE in the study by Berko et al. showed higher muscle elasticity in children after exercise $[5,8]$.

The aim of this prospective study was to assess the method of strain elastography for the evaluation of elastic properties of the musculature in muscle-healthy young adults and to investigate influencing factors on the results as well as to test the method in a cohort of muscle-healthy children. In addition to the subjective color scale analysis, the strain ratio analysis based on fat-to-muscle deformation was used for the qualitative evaluation of the elastograms.

\section{Materials and Methods}

\section{Study Cohort}

Depending on the study group, a questionnaire collected patient history data including age, sex, height, weight, handedness, footedness, sports participation units (at least one hour per week), injuries, reported pain. Consent was obtained both orally and in writing.

\section{Muscle-healthy children}

Twenty-five muscle-healthy children ( 9 girls, 12 boys) were prospectively examined. The average age was $6.4 \pm 2.4$ years; BMI was $17.3 \pm 3.5 \mathrm{~kg} / \mathrm{m}^{2}$. Fifteen children demonstrated a dominant right arm; 3 exhibited a dominant left arm, and a definitive statement could not be made for 3 children. Twelve children indicated using a dominant right foot, 1 child predominantly used the left leg, and 8 children could not definitively determine dominance.

Due to a lack of compliance, only the examination results of 21 children could be taken into account for statistical evaluation, as movement artifacts influenced the images.

\section{Muscle-healthy adults}

Twenty-two muscle-healthy adults ( 11 women and 11 men) were elastographically examined. On average the volunteer subjects were $24.4 \pm 2.8$ years old and exhibited a BMI of $21.8 \pm 1.9 \mathrm{~kg} / \mathrm{m}^{2}$. Right handedness was reported by 19 subjects, 4 reported a dominant left hand. Likewise, 18 subjects indicated using the right foot predominantly; 4 used the left foot. On average the subjects engaged in sports $2.8 \pm 1.4$ times per weeks for longer than one hour. All elastographic images could be included in the statistical evaluation.

\section{Inclusion/Exclusion Criteria}

Subjects with diseases or abnormalities of the musculoskeletal system such as muscle pain, fasciculations, inflammatory skin changes at the examination sites or operations on the extremities in the last 6 months were excluded. Adult subjects with a BMI > 25 were excluded; in obese patients, sufficient deformation in deeper layers of muscle tissue is not possible [3]. Only those images were evaluated which had been carried out in a standardized manner were included in the statistical analysis.

\section{Ethics Committee Approval}

This prospective study was positively evaluated by the locally responsible ethics committee. 


\section{Investigative Methods}

After the application specialist optimized the device settings, the examinations were carried out by an examiner intensively trained in strain elastography for four weeks on the iU22 sonography unit by Philips with an L12-5 MHz linear transducer. The examination included both sides of the biceps brachii muscle, quadriceps femoris muscle and the medial and lateral gastrocnemius muscles. The measurements of the biceps brachii muscle and quadriceps femoris muscle were performed in a relaxed supine position, while the gastrocnemius muscle was examined in a prone position with feet hanging over the examination table. The muscles to be examined were initially adjusted according to the muscle fiber orientation in the B-mode procedure. In order to perform standardized measurements, the center point between the attachment point and origin of the muscle was selected as the measurement location. The transducer was oriented at a $90^{\circ}$ angle to the body surface to be examined with moderate pressure (readable from the real time compression feedback bar of the monitor). Both the B-mode image and the elastogram were displayed in dual image mode in order to generate reproducible standardized cine clips of approximately $5-10$ seconds. The ROI box was set to the maximum image size.

Whereas in children strain USE measurements were performed only at rest, measurements in adults were performed after a resting phase as well as after muscular stress. Like Berko et al., dumbbells with weights between $2 \mathrm{~kg}$ and $5 \mathrm{~kg}$ were used for the biceps brachii muscle with a repetition rate of 20 - 50 stretching and bending movements until individual muscular fatigue was induced [8]. The quadriceps femoris muscle was stressed by tension during wall sitting (thigh at an angle of $90^{\circ}$ ) (between 30 and 60 seconds). The gastrocnemius muscle was stressed by bouncing up and down (between 60 - 100 seconds) on tiptoes.

\section{Assessment}

\section{Color scale analysis}

Following the approach of Berko et al., evaluation of the cine clips was carried out using a 5-point color scale [8] by consensus of two pediatric radiologists experienced in strain elastography. The dominant color within the muscle was identified and assigned and interpreted according to the color scale ( $\nabla$ Fig. 1 ). For this strain elastography study, red was defined as high elasticity (soft tissue) and blue as low elasticity (stiff tissue). A score of 1 was defined as the highest elasticity, a score of 5 as the lowest elasticity (see $>$ Fig. 1) [8].

\section{Strain ratio analysis}

The cine clips were semi-quantitatively evaluated using QLAB (Philips) quantification software. The strain ratio was derived from $\frac{\text { Fat deformation }}{\text { Muscle deformation }}$. Thirty images within the cine clips were selected in which examiner pressure was most consistent. One Region Of Interest (ROI) was placed in the fatty tissue area, another $\mathrm{ROI}$ of equal size in the muscle tissue. QLAB quantification software determined percentage values for deformation in fat (1) and muscle tissue (2) and calculated the strain ratio from median 1/median 2 (see $>$ Fig. 2 ).

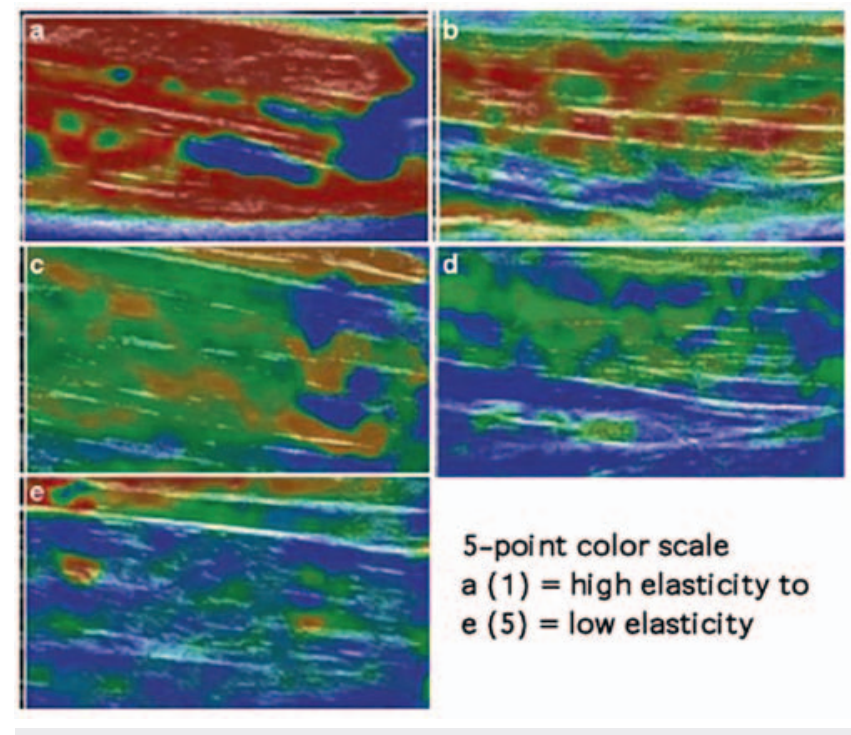

- Fig. 1 5-Point Colour Scale. Red $(\mathrm{a}=1)$ describes high elasticity, blue $(e=5)$ describes low elasticity.

\section{Statistics}

SPSS, version 23 and Microsoft Excel were used for statistical analysis. The level of significance was set at $p<0.05$. After detailed statistical consultation, the arithmetic mean values, standard deviations and coefficients of variation ( $\left.\frac{\text { Standard deviation }}{\text { Mean }}\right)$ were analyzed analogously to earlier studies $[9,10]$. The Wilcoxon test for combined samples was used to compare the elasticity changes before and after exercise in muscle-healthy subjects. Correlation with age, BMI, handedness, footedness, etc., was performed for each group using Spearman's nonparametric test for resting values and under stress. The Mann-Whitney $U$ test was used for independent samples, such as comparison between the individual study groups or differences between the sexes.

\section{Results}

\section{Muscle-healthy Adults}

Both the color scale analysis and the strain ratio analysis showed that there is a tendency towards higher elasticity after exercise in the muscles of healthy adults. In the elastograms ( $>$ Fig. 3 ), this is shown as an increase in the red color component compared to the resting chart.

\section{Color scale analysis}

A comparison between the individual muscle groups showed an average value of 2.75 for the biceps brachii muscle when measured after the resting phase. This value clearly differs from those of the leg muscles, which showed on average 1.78 points on the color scale during the resting phase. The tendency towards greater elasticity after muscular stress was observed for all muscle groups. A significant difference was demonstrated for the left biceps brachii muscle $(p=0.003)$. The standard deviation (SD) ranged between \pm 0.45 and \pm 0.69 , the coefficients of variation 


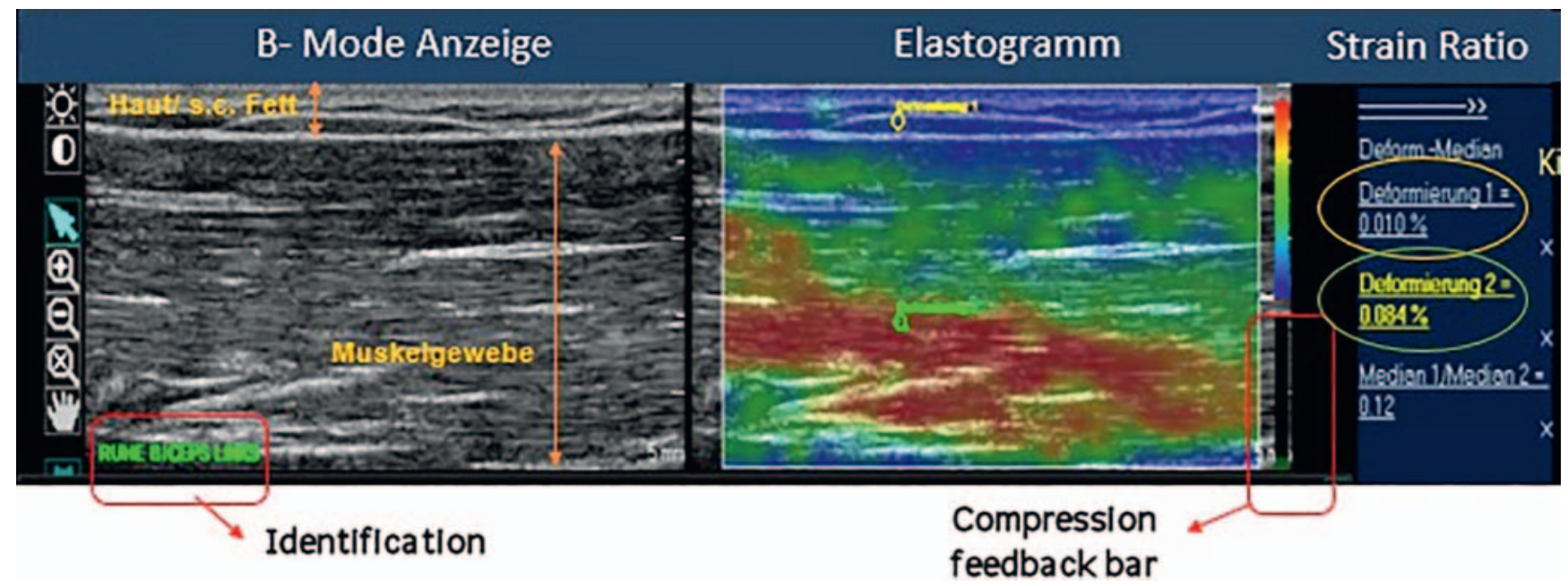

- Fig. 2 Position of the Region oof Interest (ROI) in fat (yellow marking) and muscle tissue (green marking). In this example the value of deformation is higher in muscle tissue $(0.084 \%)=$ denominator, than in fatty tissue $(0.010 \%)=$ numerator, hereby resulting in a low strain ratio value.

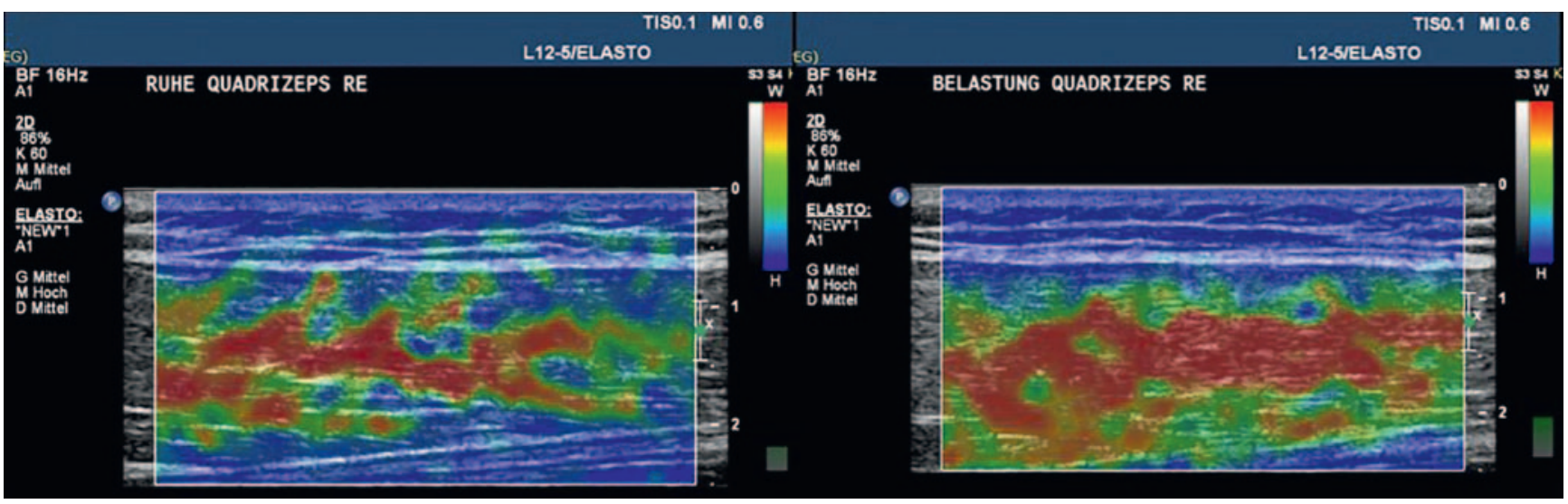

- Fig. 3 Elastogrammes of the M. rectus femoris of a 25-year old healthy adult before (left) and after (right) exercise. After exercise there is apparently a higher content of red colour (high elasticity) than before exercise.

between $0.19-0.39$. T Table 1 summarizes the results of the color scale analysis.

Strain ratio analysis

The differences between the measurements at rest and after exercise were significantly different, both for the biceps brachii muscle (right $p=0.013$, left $p=0.028$ ) and the quadriceps femoris muscle (right $p=0.009$ and left $p=0.015$ ). The SD varied from the mean on average by \pm 0.18 . The average coefficients of variation were 0.62 . $>$ Table 2 summarizes the results of the strain ratio analysis.

\section{Correlation of muscle elasticity}

Spearman's nonparametric correlation analysis showed that changes in elasticity values (prior to, after exercise) of musclehealthy adults were not significantly correlated with the variables age, BMI, dominant handedness, footedness or exercise activity.

However, evaluation of the elastograms based on the color scale analysis revealed significantly different trends between the sexes in the resting values of the right biceps muscle $(p=0.002$; average value women 2.36 ; men 3.00 ), the right quadriceps $(p=0.01$; average value women 1.32 ; men 2.10$)$ and the gastrocnemius muscles on both sides (right $p=0.001$, average value women 1.32; men 2.14; left $\mathrm{p}=0.003$, average value women 1.6; men 2.32). Men always exhibited greater values on the color scale. Likewise, the resting values of the strain ratio analysis exhibited significantly different central tendencies between the sexes on both sides of the quadriceps femoris muscle (right $p=0.016$, average value women 0.36 ; men 0.17 ; left $p=0.000$, average value women 0.47 ; men 0.17 ). Women demonstrated higher values in the strain ratio analysis.

In addition, strain ratio analysis revealed a tendency towards a greater distribution of values in muscle-healthy female subjects.

\section{Muscle-healthy Children}

Significant differences in the elasticity of the skeletal muscles between different groups of subjects (adults and children) could also be detected in the color scale analysis and strain ratio analysis. 
- Table 1 Parameters of the color scale analysis in adults with healthy muscles before and after exercise (median and standard deviation).

\begin{tabular}{|l|l|l|l|l|}
\hline & pre-exercise $\mathbf{( n = 2 2 )}$ & post-exercise $\mathbf{( n = 2 2 )}$ & differential & p value \\
\hline right biceps & $2.68 \pm 0.50$ & $2.52 \pm 0.63$ & +0.16 & 0.172 \\
\hline left biceps & $2.82 \pm 0.61$ & $2.41 \pm 0.57$ & +0.41 & $\mathbf{0 . 0 0 3}$ \\
\hline right quadriceps & $1.70 \pm 0.68$ & $1.66 \pm 0.64$ & +0.04 & 0.681 \\
\hline left quadriceps & $1.73 \pm 0.57$ & $1.68 \pm 0.52$ & +0.05 & 0.917 \\
\hline right gastrocnemius & $1.73 \pm 0.53$ & $1.84 \pm 0.45$ & -0.11 & 0.160 \\
\hline left gastrocnemius & $1.95 \pm 0.69$ & $1.93 \pm 0.60$ & +0.02 & 0.808 \\
\hline
\end{tabular}

- Table 2 Deformation quotient analysis in adults with healthy muscles (median and standard deviation).

\begin{tabular}{|l|l|l|l|l|}
\hline & pre-exercise $\mathbf{( n = 2 2 )}$ & post-exercise $\mathbf{( n = 2 2 )}$ & differential & $\mathbf{p ~ v a l u e ~}$ \\
\hline right biceps & $0.22 \pm 0.11$ & $0.17 \pm 0.10$ & 0.05 & $\mathbf{0 . 0 1 3}$ \\
\hline left biceps & $0.24 \pm 0.13$ & $0.17 \pm 0.55$ & 0.07 & $\mathbf{0 . 0 2 8}$ \\
\hline right quadriceps & $0.27 \pm 0.20$ & $0.20 \pm 0.12$ & 0.07 & $\mathbf{0 . 0 0 9}$ \\
\hline left quadriceps & $0.32 \pm 0.31$ & $0.20 \pm 0.14$ & 0.12 & $\mathbf{0 . 0 1 5}$ \\
\hline right gastrocnemius & $0.20 \pm 0.10$ & $0.16 \pm 0.06$ & 0.04 & 0.245 \\
\hline left gastrocnemius & $0.20 \pm 0.12$ & $0.20 \pm 0.19$ & 0.00 & 0.650 \\
\hline
\end{tabular}

\section{Color scale analysis}

Statistically significant differences were recorded for the quadriceps femoris muscle on both sides $(p=0.001)$ and the right lateral gastrocnemius muscle $(p=0.050)$. The muscles of adults had a higher elasticity than those of children (see $>$ Table 3 ).

\section{Strain ratio analysis}

Significant differences $(p<0.05)$ between children and adults were found for all muscle groups (see $>$ Table 4 ).

\section{Discussion}

\section{Ultrasound elastography}

Elastography is an advanced and promising diagnostic method for assessing the stiffness of organs and soft tissues, especially for use in children, as it is non-invasive, low-risk, cost-effective and can be easily integrated into everyday clinical practice $[1,8]$. However, the publications available so far on elasticity measurement of skeletal muscle using USE show a high heterogeneity in their study designs $[5,6,8,12-14]$.

One aim of this work was to employ strain USE to determine the elasticity of skeletal muscles in different muscle groups of adults in a standardized way in order to identify sources of error and establish the method. Future studies could be based on the detailed description of the investigation technique we use (see the Materials and Methods section) [15]. A standardized, comfortable position and good compliance by the examinee as well as the standardized application of technique by an experienced examiner are prerequisites for obtaining well-reproducible measurement results $[15,16]$.

The real-time compression feedback bar in the strain elastography display was very helpful in estimating the standardized manual pressure application. Artifacts can occur in the elastogram if the pressure is uneven (see $\bullet$ Fig. 4) $[4,17]$ which could result in erroneous conclusions.

The problem is that tissue lying more than $5 \mathrm{~cm}$ deep is not sufficiently deformed, and the ultrasound waves may be attenuated $[1,18]$. Drakonaki et al. show that so far there is no consensus regarding the size of the ROI box [4]. In this study, the ROI box was consistently adjusted to maximum size to include influencing structures.

Using the example of the tendon of the gastrocnemius muscle, De Zordo et al. showed that strain ultrasound elastography is highly sensitive and specific with regard to clinical findings (e. g. crepitation, pain, edema) and B-image sonography $[4,12,19]$. The correlation to the fundamental ultrasound was 0.89 [20]. In 2012, Chino et al. investigated the possibility of using strain elastography to study muscle architecture and elasticity, and came to a positive conclusion regarding the reliability and validity of the method [7]. Other elastography techniques have not been commonly used to assess muscle elasticity, since the particularities of the muscular architecture, such as non-linear stress-strain behavior, viscoelasticity and anisotropy of the musculature can falsify the values of shear wave velocity (ARFI elastography, transient elastography). It should be emphasized, for example, that direction-dependent differences in elasticity are measured with differ- 
- Table 3 Resting values of the color scale analysis in adults and children with healthy muscles (median and standard deviation).

\begin{tabular}{|l|l|l|l|l|}
\hline & healthy adults $\mathbf{( n = 2 2 )}$ & healthy children (n=21) & differential & p value \\
\hline right biceps & $2.68 \pm 0.50$ & $2.85 \pm 0.75$ & -0.17 & 0.519 \\
\hline left biceps & $2.82 \pm 0.60$ & $3.15 \pm 0.50$ & -0.33 & 0.067 \\
\hline right quadriceps & $1.70 \pm 0.68$ & $2.85 \pm 0.67$ & -1.15 & $\mathbf{0 . 0 0 1}$ \\
\hline left quadriceps & $1.73 \pm 0.57$ & $2.95 \pm 0.76$ & -1.22 & $\mathbf{0 . 0 0 1}$ \\
\hline right gastrocnemius & $1.73 \pm 0.53$ & $2.15 \pm 0.58$ & -0.42 & $\mathbf{0 . 0 5 0}$ \\
\hline left gastrocnemius & $1.95 \pm 0.69$ & $2.00 \pm 0.60$ & -0.06 & 0.958 \\
\hline
\end{tabular}

- Table 4 Resting values of the deformation quotient analysis in adults and children with healthy muscles (median and standard deviation).

\begin{tabular}{|l|l|l|l|l|}
\hline & healthy adults $\mathbf{( n = 2 2 )}$ & healthy children (n=21) & differential & $\mathbf{p ~ v a l u e ~}$ \\
\hline right biceps & $0.22 \pm 0.11$ & $0.62 \pm 0.45$ & -0.40 & $\mathbf{0 . 0 0 0}$ \\
\hline left biceps & $0.24 \pm 0.13$ & $0.59 \pm 0.55$ & -0.35 & -0.35 \\
\hline right quadriceps & $0.27 \pm 0.20$ & $0.62 \pm 0.49$ & -0.38 & $\mathbf{0 . 0 0 9}$ \\
\hline left quadriceps & $0.32 \pm 0.31$ & $0.70 \pm 0.51$ & -0.28 & $\mathbf{0 . 0 0 1}$ \\
\hline right gastrocnemius & $0.20 \pm 0.10$ & $0.48 \pm 0.48$ & -0.22 & $\mathbf{0 . 0 0 1}$ \\
\hline left gastrocnemius & $0.20 \pm 0.12$ & $0.42 \pm 0.40$ & $\mathbf{0 . 0 2 1}$ \\
\hline
\end{tabular}

ent courses of the muscle fiber orientations and that this can lead to errors in the elasticity measurement, since the shear waves propagate at a higher speed if they move parallel and not perpendicular to anatomical structures $[1,4,21]$.

\section{Evaluation procedure}

Different evaluation methods of the elastograms were used in this study in addition to various investigative techniques.

The analysis of cine loops (short video sequences) instead of individual images yields a more comprehensive insight into the elasticity distribution [4]. Color scale analysis proved to be a simple and reliable means of evaluating the video sequences. The coefficients of variation of the color scale evaluation varied in total between $0.16-0.39$, while the coefficients of variation of the strain ratio analysis (values between $0.38-1.26$ ) were significantly higher.

This result confirms that the observation of a relatively large muscle section (color scale) is less susceptible to interference with lower compliance than analysis using strain ratios (very small examined section), even if the latter has a statistically higher scale level. Since the color scale of Berko et al. is only ordinally scaled and thus fewer mathematical statements can be made than, for example, an interval or ratio scale, the color scale should be revised in order to raise it to a higher scale level. Objectification of the evaluation of the color charts by using color pixel histograms could be a useful way to reduce the subjectivity of this form of analysis.

Strain ratio analysis may deliver different results depending on the examiner due to manual placement of the ROI. As a reference, subcutaneous adipose tissue was chosen, as this had already been

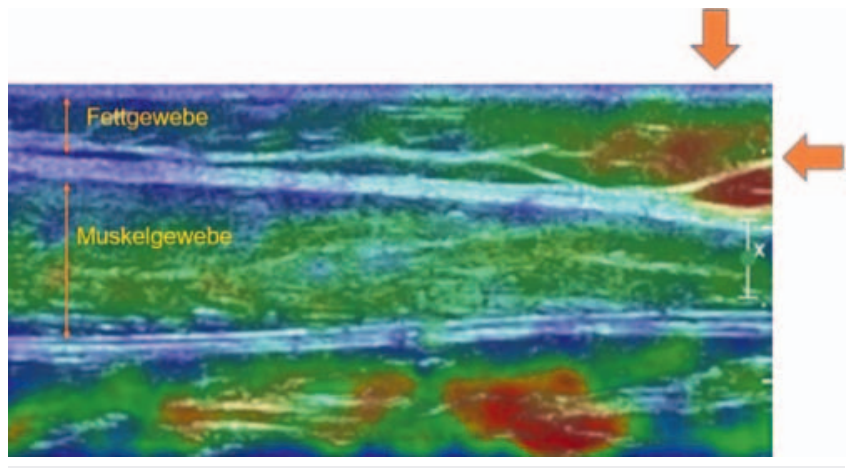

- Fig. 4 Elastogramme with marking of artifacts through inconsistent pressure at the image border.

proven in the evaluation of the strain elastography in tendons of the gastrocnemius muscle [4].

\section{Results of muscle-healthy adults}

Variations in elasticity between the arm and leg muscles were observed in the present study [8]. This could be explained by differences in muscle function. While the biceps brachii muscle is counted among the movement muscles, the rectus femoris muscle is an extensor muscle, demonstrating differences in the proportion of type 1 (slow) and type 2 (rapid) muscle fibers, size of the motor units and capillarisation [22]. Berko et al. discuss the differences in the various development of muscle mass, strength and daily exercise [8]. It remains unclear why the different elasti- 
cities between the upper and lower extremities could not be demonstrated by strain ratio analysis with good compliance by the adults.

The significant influence of muscular stress on the elasticity of biceps brachii and rectus femoris muscle observed in our study by strain ratio analysis could be explained by increased blood flow due to vasodilation within the muscle [23]. In their studies, Inami et al. [13] and Berko et al. [8] likewise describe greater elasticity after exercise. In addition, Inami et al. observed hardening of the musculature when measuring in the contracted state [13]. Strain elastography can therefore not only detect differences in muscle architecture, but also indicate an increase in tone or possibly changes in blood flow. Further studies to determine muscle perfusion would be helpful in obtaining further insights into the background of the elasticity change after muscular contraction.

With regard to the dominant side, the high proportion of righthanders in the present study showed a tendency towards greater elasticity of the respective right extremity. Significant differences, as in the study by Berko et al., could not be demonstrated [8].

The strain ratio in women tended to show a higher spread of elasticity values, which can be explained by a higher variability of muscle fiber types and sizes compared to men [24]. Likewise, the resting values of the sexes differed in elasticity which could be attributed to the different fat content and compression of the muscle.

\section{Results of muscle-healthy children}

Due to insufficient compliance, four children were excluded from the study. The fact that larger standard deviations (children \pm 0.48 , adults \pm 0.16 ) were found in children in the strain ratio analysis underlines the need for good cooperation in the implementation and shows its limits.

Color scale analysis and strain ratio analysis revealed significant differences between muscle-healthy children and adults. Compared to muscle-healthy children, the color scale analysis of adults revealed $12.4 \%$ greater elastic musculature and $55.6 \%$ in the strain ratio analysis. The values of children showed similar elasticity values on the color scale as in the muscle-healthy children in the study by Berko and colleagues, which on average was 2.7 points (Berko: 2.9 points). Reasons for age-dependent differences in elasticity could lie in the age-dependent component of the different muscle fibers, muscle mass, collagen content in the muscle and varying fat distribution [25].

\section{Limitations of the study}

Our study has some limitations which should be considered in subsequent studies. Since at the time of the investigations there was no sufficiently documented literature to make assumptions, e. g. about expected mean values (previous studies contradict each other); after statistical consultation, a sample size calculation using G-Power was omitted. Only a small number of subjects could be examined, therefore the statistical significance is limited. Subsequent studies should preferably be designed with a larger number of cases, multi-center studies would be conceivable. Likewise, despite ordinal scaled values of the semi-quantitative color scale analysis, the arithmetic mean values were chosen instead of the medians in order to make the results more comparable with other studies. Although this will produce more realistic results, it will also take account of outliers. In addition, intra- and interobserver validation would be desirable for further studies, as our study relies only on prior studies $[4-8,12,20]$.

\section{Conclusions}

It is difficult to compare results due to the heterogeneity of the investigative design in existing publications on elastography. This study therefore focused on standardization of the performance and evaluation of muscle elastograms. Sources of error were uncovered, suggested solutions offered and an optimized investigation technique was described in detail.

Color scale and strain ratio analyses proved to be effective techniques for analyzing the elasticity of different muscle groups in adults and children. When the prerequisites for standardized measurements are met, strain elastography is a basically simple, inexpensive and rapid diagnostic procedure without ionizing radiation to assess muscle elasticity. In order to establish the method, however, case number planning should be performed first and larger studies should follow.

\section{CLINICAL RELEVANCE}

- As a non-invasive method, ultrasound elastography can provide important insights into muscle elasticity.

- Up to now, the diagnosis and evaluation of motor function and musculature have been based primarily on subjective classification systems [4, 26].

- Since early intervention has a positive influence on the course of spastic musculature, innovative non-invasive diagnostic methods are sought to detect changes in stiffness at an early stage and to objectively assess the course of therapy [27].

\section{Conflict of Interest}

The authors declare that they have no conflict of interest.

\section{References}

[1] Stenzel M, Mentzel HJ. Ultrasound elastography and contrast-enhanced ultrasound in infants, children and adolescents. European journal of radiology 2014; 83: 1560 -1569. doi:10.1016/j.ejrad.2014.06.007

[2] Brandenburg JE, Eby SF, Song P et al. Ultrasound elastography: the new frontier in direct measurement of muscle stiffness. Archives of physical medicine and rehabilitation 2014; 95: 2207-2219. doi:10.1016/ j.apmr.2014.07.007

[3] Lorenzen J, Sinkus R, Adam G. Elastography: Quantitative imaging modality of the elastic tissue properties. RoFo: Fortschritte auf dem Gebiete der Rontgenstrahlen und der Nuklearmedizin 2003; 175: 623-630. doi:10.1055/s-2003-39199

[4] Drakonaki EE, Allen GM, Wilson DJ. Ultrasound elastography for musculoskeletal applications. The British journal of radiology 2012; 85: 1435 1445. doi:10.1259/bjr/93042867 
[5] Yanagisawa O, Niitsu M, Kurihara T et al. Evaluation of human muscle hardness after dynamic exercise with ultrasound real-time tissue elastography: a feasibility study. Clinical radiology 2011; 66: 815-819. doi:10.1016/j.crad.2011.03.012

[6] Niitsu M, Michizaki A, Endo A et al. Muscle hardness measurement by using ultrasound elastography: a feasibility study. Acta radiologica (Stockholm, Sweden: 1987) 2011; 52: 99 -105. doi:10.1258/ ar.2010.100190

[7] Chino K, Akagi R, Dohi M et al. Reliability and validity of quantifying absolute muscle hardness using ultrasound elastography. PloS one 2012; 7: e45764. doi:10.1371/journal.pone.0045764

[8] Berko NS, Fitzgerald EF, Amaral TD et al. Ultrasound elastography in children: establishing the normal range of muscle elasticity. Pediatric radiology 2014; 44: 158 - 163. doi:10.1007/s00247-013-2793-z

[9] Koschack J. Standard Deviation and Standard Error: the Small But Important Difference Standardabweichung und Standardfehler: Der kleine, aber feine Unterschied. Allg Med 2008; 84: 258-260

[10] Lange S, Bender R. Median oder Mittelwert? Dtsch med Wochenschr 2007; 132: e1-e2. doi:10.1055/s-2007-959024

[11] Cohen J. A power primer. Psychological bulletin 1992; 112: 155 - 159

[12] De Zordo T, Chhem R, Smekal V et al. Real-time sonoelastography: findings in patients with symptomatic achilles tendons and comparison to healthy volunteers. Ultraschall in der Medizin (Stuttgart, Germany: 1980) 2010; 31: 394-400. doi:10.1055/s-0028-1109809

[13] Inami T, Tsujimura T, Shimizu T et al. Relationship between isometric contraction intensity and muscle hardness assessed by ultrasound strain elastography. European journal of applied physiology 2017; 117: 843 852. doi:10.1007/s00421-016-3528-2

[14] Kwon DR, Park GY. Diagnostic value of real-time sonoelastography in congenital muscular torticollis. Journal of ultrasound in medicine: official journal of the American Institute of Ultrasound in Medicine 2012; 31: $721-727$

[15] Ewertsen C, Carlsen JF, Christiansen IR et al. Evaluation of healthy muscle tissue by strain and shear wave elastography - Dependency on depth and ROI position in relation to underlying bone. Ultrasonics 2016; 71 : 127 - 133. doi:10.1016/j.ultras.2016.06.007

[16] Martino F, Silvestri E, Grassi W et al. Musculoskeletal Sonography; Springer Verlag; 2007
[17] Ooi CC, Malliaras P, Schneider ME et al. “Soft, hard, or just right?” Applications and limitations of axial-strain sonoelastography and shear-wave elastography in the assessment of tendon injuries. Skeletal radiology 2014; 43: 1 - 12. doi:10.1007/s00256-013-1695-3

[18] Lorenzen J, Sinkus R, Adam G. Elastographie: Quantitative Bildgebung der elastischen Gewebeeigenschaften. Fortschr Röntgenstr 2003; 175: $623-630$

[19] Drakonaki EE, Allen GM. Magnetic resonance imaging, ultrasound and real-time ultrasound elastography of the thigh muscles in congenital muscle dystrophy. Skeletal radiology 2010; 39: 391 - 396. doi:10.1007| s00256-009-0861-0

[20] Drakonaki EE, Allen GM, Wilson D]. Real-time ultrasound elastography of the normal Achilles tendon: reproducibility and pattern description. Clinical radiology 2009; 64: 1196-1202. doi:10.1016/j. crad.2009.08.006

[21] Gennisson JL, Deffieux T, Mace E et al. Viscoelastic and anisotropic mechanical properties of in vivo muscle tissue assessed by supersonic shear imaging. Ultrasound in medicine \& biology 2010; 36: 789-801. doi:10.1016/j.ultrasmedbio.2010.02.013

[22] Schünke M, Schult E, Schumacher U et al. Prometheus-Allgemeine Anatomie und Bewegungssystem; 2007

[23] Clifford PS, Tschakovsky ME. Rapid vascular responses to muscle contraction. Exerc Sport Sci Rev 2008; 36: 25 -29. doi:10.1097/jes. 0b013e31815ddba4

[24] Miller AE, MacDougall JD, Tarnopolsky MA et al. Gender differences in strength and muscle fiber characteristics. European journal of applied physiology and occupational physiology 1993; 66: 254-262

[25] Tschakovsky ME, Saunders NR, Webb KA et al. Muscle blood-flow dynamics at exercise onset: do the limbs differ? Medicine and science in sports and exercise 2006; 38: 1811 -1818. doi:10.1249/01. mss.0000230341.86870.4f

[26] Hadders-Algra M, Boxum AG, Hielkema T et al. Effect of early intervention in infants at very high risk of cerebral palsy: a systematic review. Developmental medicine and child neurology 2016. doi:10.1111/ dmcn. 13331

[27] Strassburg HM. Behandlungskonzept bei Kindern mit infantiler Zerebralparese. In: Leitlinien der Kinder- und Jugendmedizin, 2015; pp. R5.1 - R5.6. DOI:10.1016/B978-3-437-22061-6.50584-X https:// www.dgspj.de/wp-content/uploads/service-archiv-leitlinie-icp-2004.pdf 